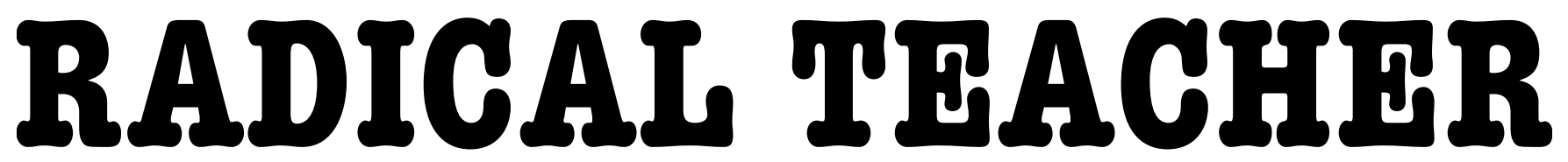

A SOCIALIST, FEMINIST, AND ANTI-RACIST JOURNAL ON THE THEORY AND PRACTICE OF TEACHING

\title{
Teaching Note When Did You Know You Were Straight?: Teaching with the Heterosexual Questionnaire
}

by Jessica Ann Vooris

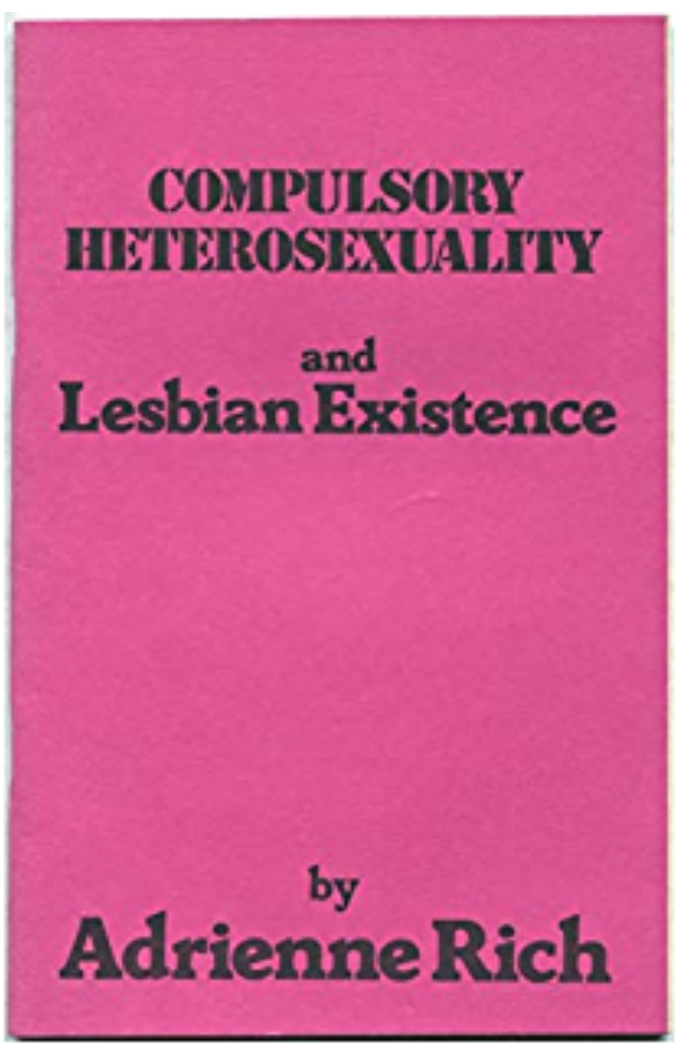

"COMPULSORY HETEROSEXUALITY" BY ADRIENE RICH 
hat do you think caused your heterosexuality?" an audience member asks the straight panelists. "Uh, I don't know, I just am," says one of them with a shrug. Another reflects on the fact that he grew up in a religious household so he didn't have a choice when he was younger, but as he has gotten older being straight still feels right to him. A third says that she has always liked boys, but notes that she saw mostly straight relationships on television, so didn't know there were other options.

My students are participating in an activity that I facilitate in my LGBTQ Studies courses, a panel of straightidentified students, answering questions from the Heterosexual Questionnaire by Martin Rochlin. The class is Intro to Sexuality Studies, at a small, predominantly white, liberal arts institution, and includes WGSS majors, as well as students who are just interested in learning more about sexuality and LGBTQ identities. Although it is an introductory course, students range from first-years to seniors.

The panel activity highlights heterosexism and heterosexual privilege, provides an opportunity to talk about satire and queer humor, and is a useful way to engage with concepts from class readings. The Heterosexual Questionnaire was first written in 1972, and challenges negative stereotypes about lesbian and gay people. It takes the questions that lesbian and gay folks are often asked, and addresses them to straight people instead. The questions ask them to explain and justify their sexuality and the choices they have made about their heterosexual life-style. For example:

"What do you think caused your heterosexuality?" "To whom have you disclosed your heterosexual
tendencies?

"With all the societal support for marriage, the divorce rate is spiraling. Why are there so few stable relationships among heterosexuals?"

"Why do you attribute heterosexuality to so many famous lesbian and gay people? Is it to justify your own heterosexuality?"

The Questionnaire denaturalizes heterosexuality, and challenges straightness as the norm. It continues to be relevant almost 50 years since it was first published, and has been re-published in many Women's and Gender Studies textbooks, and on various websites online. I have used it in many of my classes including Intro to Women's and Gender Studies, LGBTQ Identities and Communities, and LGBTQ Life Trajectories. I have taught at several small liberal arts colleges, as well as at large state universities, and the activity has worked well in both elective courses where students are already invested in the topics of the course, as well as general education courses where students are new to the subject of gender and sexuality. I have found it particularly useful to use alongside class texts such as Homophobia: A Weapon of Sexism by Suzanne Pharr (1988), "Compulsory Heterosexuality" by Adriene Rich (1980), Straight: A Short History of Heterosexuality by Hanne Blank (2012), and Dykes to Watch Out For by Alison Bechdel (2008).

While it is possible to spur discussion by simply handing out the questionnaire and asking students to connect it to class texts, I have facilitated more in-depth and rich discussions by organizing a panel of straight students who then answer questions that their fellow students select from the list. I first ask for a few volunteers (2-5, depending on class size) who identify as straight and are willing to participate on a panel and answer questions about their sexuality. I then pass around the Questionnaire to the rest of the students, and ask them to pick a few questions to ask the panelists. I ask the panel volunteers to think carefully about the questions and to answer as honestly and clearly as they can, but reassure them that they are always free to say "I don't know," or to skip questions that they do not feel comfortable answering.

The volunteers are taking a risk, and usually are a bit nervous, but are also eager to share their experiences. There is often a lot of laughter during the exercise, as to be expected with some of the questions, but the panelists have always tried to answer the questions sincerely. Students eagerly raise their hands to read out the questions, and queer-identified students in particular seem to find great satisfaction in the exercise. In the conversation that follows, many of my LGBTQ students discuss how that they have been asked similar questions and how hurtful it can feel to have their sexuality challenged. They appreciate the opportunity to turn those questions around and present them to those who are straight-identified, and it is a good way to talk about heterosexism, and the ways that straightness is accepted as a norm.

The panelists often reflect on the fact that no one has asked these questions to them before and that they haven't really thought about what it means to be straight. Some of the questions confuse them, and they note that some of the questions touch on private information they don't want to share. Again, this provides the opportunity to talk about privilege and power, and how straight people are not asked to validate their sexuality.

Overall, the exercise is an effective way to make heterosexism and homophobia visible, especially as the questions touch on the different systemic ways that LGBTQ folks are denied equal treatment in terms of marriage, jobs, schools, and therapists' offices. In the discussion afterward, I make sure that we connect specific questions and the panelists' responses to the course readings. I also talk about what was happening at the time that the Questionnaire was first written in the 1970s post-Stonewall: the first Pride marches, the removal of homosexuality from the DSM in 1973, and the Anita Bryant "Save Our Children" campaign in Florida. We then reflect on the ways that LGBTQ rights have changed, and also how homophobia continues to affect the LGBTQ community. 
The Questionnaire also opens up a conversation about satire and queer humor as resistance. The first question I always ask students during the discussion period after the panel is: "What kind of writing is this?" The first few times I handed out the Questionnaire, a few students were offended and responded angrily to the list, as they didn't recognize it as satire. While we were able to reach an understanding of what the Questionnaire was trying to accomplish through the following discussion, I have found that it is better to address the tone of the writing right at the start of discussion. That way, we are all approaching it from the same perspective before jumping into a deeper conversation about specific questions and the experience of participating in the activity. It also provides a moment to talk about how the queer community has often used humor, and "camp" humor in particular, as a way to fight back against homophobia.

My final piece of advice for anyone who would like to do this activity is to be careful that you do not unintentionally out LGBTQ students if you have a small class. Even though the panel is for heterosexual volunteers, queer students who do not volunteer may feel uncomfortable or feel that they are being outed by virtue of not being on the panel. When I did this exercise in a small class of 10 , most of the students had already disclosed their identities within the first few weeks of class, so I wasn't worried about outing any students. Given the small size of the class, I wasn't sure if anyone would feel comfortable coming forward for the panel, and I noted that if no one wanted to volunteer, we would just discuss the text as a whole class. However, I ended up with two volunteers, and it went really well. I think in many ways this exercise was a turning point for students in that class in terms of creating a more open environment for discussion, by facilitating trust between students.

\section{References}

Bechdel, Alison. 2008. The Essential Dykes to Watch Out For. Boston: Houghton Mifflin Harcourt.

Blank, Hanne. 2012. Straight: the surprisingly short history of heterosexuality. Boston: Beacon Press.

Pharr, Suzanne. 1988. Homophobia: A Weapon of Sexism.

Rochlin, Martin. 1992. "The Heterosexual Questionnaire." Homophobia: How we all pay the price. Warren J. Blumenfeld (Ed.). Beacon Press: Boston, USA. pages 203-204.

Rochlin, Martin. 1972. "The Heterosexual Questionnaire." The University of Wisconsin Gender and Sexuality Center. Web. Accessed: July 18, 2020.

Rich, Adrienne 1980. "Compulsory Heterosexuality and Lesbian Existence". Signs: Journal of Women in Culture and Society. 5 (4): 631-660. University of Chicago Press Journals (cc) EY-NG-ND

ULLS D-Sorle
This work is licensed under a Creative Commons Attribution-Noncommercial-No Derivative Works 3.0 United States License.

This journal is published by the University Library System of the University of Pittsburgh as part of its D-Scribe Digital Publishing Program, and is cosponsored by the University of Pittsburgh Press. 